\title{
Avastin in myopic choroidal neovascularisation: is age the limit?
}

David Wong and Kenneth K W Li

Br J Ophthalmol 2008 92: 1011-1012

doi: 10.1136/bjo.2007.135681

Updated information and services can be found at:

http://bjo.bmj.com/content/92/8/1011.1.full.html

Topic collections Articles on similar topics can be found in the following collections

\author{
Choroid (396 articles) \\ Optic nerve (494 articles) \\ Retina (1082 articles) \\ Optics and refraction (336 articles) \\ Epidemiology (4999 articles)
}

\section{Notes}

To request permissions go to:

http://group.bmj.com/group/rights-licensing/permissions

To order reprints go to:

http://journals.bmj.com/cgi/reprintform

To subscribe to BMJ go to:

http://journals.bmj.com/cgi/ep 


\title{
Avastin in myopic choroidal neovascularisation: is age the limit?
}

\author{
David Wong, ${ }^{1,2}$ Kenneth K W Li
}

There are a growing number of publications supporting the use of Avastin (bevacizumab) for choroidal neovascularisation (CNV) secondary to pathological myopia (table 1). ${ }^{1-8}$ In this issue, Arias et al (see page 1035) reported a prospective study of 17 patients; ${ }^{9}$ at the 6-month follow-up, the mean Early Treatment Diabetic Retinopathy Study visual acuity improved by 8.4 letters $(p=0.04)$, and the mean optical coherence tomography (OCT) foveal thickness decreased by $79.6 \mu \mathrm{m}(p=0.002)$. Is it time to change our clinical practice? Is it time to abandon photodynamic therapy (PDT) as the first line treatment? The purist would say that the only evidence base from randomised controlled trials is still that provided by the Verteporfin in Photodynamic Therapy (VIP) Study. ${ }^{10} 11$ In this study, PDT was shown to be effective in preventing visual loss fewer than eight letters in pathological myopia in the first year when compared with sham treatment. ${ }^{10}$ However, the effect of PDT was not sustained by the end of the second year. ${ }^{11}$ Smaller case series have shown similar results. ${ }^{11}$ Other investigators have attempted to improve the efficacy of PDT by enhancing the fluence $^{13}$ or combining PDT with intravitreal triamcinolone acetonide injection. ${ }^{14}{ }^{15}$ These studies failed to persuade, either limited by the small number of patients or because the results were inconsistent.

But do all CNV secondary to pathological myopia have a similar prognosis and response to treatment? The report on the natural history of untreated CNV secondary to pathological myopia by Kojima et al is now recognised as a landmark paper. ${ }^{16}$ Using regression analysis, they investigated the prognostic factor in 54 untreated eyes in 54 patients in Japan (prior to PDT being available) and found

\footnotetext{
${ }^{1}$ Eye Institute, Li Ka Shing Faculty of Medicine, The University of Hong Kong, Hong Kong SAR, China;

${ }^{2}$ St Paul's Eye Unit, Royal Liverpool University Hospital, Liverpool, UK

Correspondence to: Professor D Wong, Royal Liverpool University Hospital, Prescot Street, Liverpool

L7 8XP, UK; shdwong@liv.ac.uk
}

that the best corrected visual acuity (BCVA) at 5 years after onset was significantly associated with patient age, CNV size and initial BCVA $(p<0.05$, Spearman correlation). In a retrospective study, Yoshida et al also examined the effect of age on the natural history of CNV secondary to pathological myopia. ${ }^{17}$ They found that patients under the age of 40 had significant better visual outcome than patients over the age of 40. Their results need to be interpreted carefully, as they included both juxtafoveal and subfoveal cases. The authors nonetheless raised the important point that the visual prognosis of CNV secondary to pathological myopia was not always consistent. The angiographic features of the CNV in patients over the age of 40 had a more profuse angiographic leakage. Other investigators have studied the effect of age on the visual outcome of treatment of CNV secondary to pathological myopia with PDT. Axer-Siegel et al, in a retrospective study, found that $50 \%$ of the older age group and $20 \%$ of the younger age group had visual loss of 15 letters or more, and the difference was significant; however, $8 \%$ of the younger patients in the series of Axer-Siegel et al continued to lose 15 or more letters despite treatment with PDT. ${ }^{18}$

In the VIP study, less than $25 \%$ improve one or more lines at 3 months. ${ }^{9}$ A treatment primarily aimed at preventing visual loss is likely to disappoint patients seeking to have their vision restored. In the wake of several case series reporting visual improvement with the use of Avastin, more and more physicians are persuaded to change from PDT to the off-label use of anti-vascular endothelial growth factor (VEGF) agents for CNV in pathological myopia. ${ }^{1-8}$ Until now, these interventional studies have relatively short follow-up of 6 months. We do not yet know whether multiple injections will eventually alter the natural history favourably.

In the absence of an evidence base derived from randomised controlled trial supporting the use of Avastin for CNV secondary to pathological myopia, in patients with good vision at least, some may feel obliged to use PDT as the firstline treatment. But in older patients, with larger subfoveal CNV and more significant visual loss, our threshold for switching to or even adding Avastin may be lowered. It is noteworthy that Arias et al found that patients aged $\leqslant 50$ years improved by a mean of 8.7 letters $(p=0.13)$, and patients older than 50 years improved by a mean of 8.3 letters $(p=0.1)$. Avastin seemed to be effective in older patients, whereas PDT might be limited by age.

The use of anti-VEGF off-label for agerelated macular degeneration is still fraught with ethical difficulties and funding problems within the National Health Service (NHS) in the UK. ${ }^{19}$ If we were to use an anti-VEGF, we of course have a choice of bevacizumab, ranibizumab and pegatanib, all of which are off-label treatments to CNV secondary to pathological myopia, and thus far, there are no publications on the efficacy of latter two agents. Rosenfeld pointed out that Genentech or Roche should not be expected to pay for an intravitreal Avastin clinical trial unless they plan to seek a labelled indication for Avastin in ophthalmology, which seems unlikely. ${ }^{20}$ Rather, the cost of such a trial is a societal responsibility of those agencies and governments that stand to benefit from preventing vision loss from neovascularisation in pathological myopia. In the UK, the Inhibit VEGF in Age-related choroidal Neovascularisation (IVAN) trial is set up to study CNV secondary to age-related macular degeneration and funded by the Health Technology Assessment Clinical Trials Programme of the UK National Institute for Health Research. ${ }^{21}$ The IVAN trial compares: (a) an inexpensive drug, bevacizumab used "off-label" with an expensive licensed drug, ranibizumab, and (b) continuous monthly treatment with reduced frequency of treatment. The trial has high research costs, but this investment by the NHS represents good value when set against potential savings to the NHS should the less expensive drug, or reduced treatment frequency, be shown to be as effective as the more expensive alternatives. The success of this trial is reliant on a network of hospitals and consultants working together. This network covers all of the UK and is perfectly positioned to mount an intravitreal Avastin trial on CNV in pathological myopia. The VIP trial was probably underpowered, recruiting 120 patients, randomising 81 patients to PDT and 36 
Table 1 Summary of published studies on the use of Avastin (bevacizumab) in the treatment of choroidal neovascularisation secondary to pathological myopia

\begin{tabular}{|c|c|c|c|c|c|}
\hline Year & Author & Study & No. of cases & Dosage $(\mathrm{mg}) / \mathrm{no}$. of injections & Follow-up period (months) \\
\hline 2006 & Laud et al ${ }^{1}$ & Case report & 4 & $1.25 / 2-3$ & 7.3 \\
\hline 2006 & Tewari et $a l^{2}$ & Case report & 1 & $1.25 / 2$ & 6 \\
\hline 2007 & Yamamoto et al ${ }^{3}$ & Retrospective & 11 & $1.25 / 1-2$ & 5.5 \\
\hline 2007 & Sakaguchi et al ${ }^{4}$ & Prospective & 8 & $1 / 1-2$ & 4.4 \\
\hline 2007 & Hernandez-Rojas et $a l^{5}$ & Prospective & 14 & $2.5 / \geqslant 1$ & 3 \\
\hline 2007 & Mandal et $a l^{6}$ & Prospective & 12 & $1.25 / 1+$ as necessary & 6 \\
\hline 2007 & Chan et $a l^{7}$ & Prospective & 22 & $1.25 / 3$ & 6 \\
\hline 2007 & Ruiz-Moreno et $\left.a\right|^{8}$ & Prospective & 26 & $1.25 / 3$ & 6 \\
\hline 2008 & Arias et al & Prospective & 17 & $1.25 / 1.1$ & 6 \\
\hline
\end{tabular}

to sham treatment. It will take the concerted effort of all the consultants in UK to recruit sufficient patients to get a meaningful result. In the mean time, we can only treat patients individually on their merit, as not all CNV secondary to pathological myopia have the same prognosis or response.

Competing interests: None.

Accepted 20 January 2008

Br J Ophthalmol 2008;92:1011-1012.

doi:10.1136/bjo.2007.135681

\section{REFERENCES}

1. Laud K, Spaide RF, Freund KB, et al. Treatment of choroidal neovascularization in pathologic myopia with intravitreal bevacizumab. Retina 2006;26:960-3.

2. Tewari A, Dhalla MS, Apte RS. Intravitreal bevacizumab for treatment of choroidal neovascularization in pathologic myopia. Retina 2006;26:1093-4.

3. Yamamoto I, Rogers $A H$, Reichel E, et al. Intravitreal bevacizumab (Avastin) as treatment for subfoveal choroidal neovascularisation secondary to pathological myopia. Br J Ophthalmol 2007;91:157-60.

4. Sakaguchi H, Ikuno Y, Gomi F, et al. Intravitreal injection of bevacizumab for choroidal neovascularisation associated with pathological myopia. Br J Ophthalmol 2007:91:161-5.

5. Hernández-Rojas ML, Quiroz-Mercado H, DalmaWeiszhausz J, et al. Short-term effects of intravitreal bevacizumab for subfoveal choroidal neovascularization in pathologic myopia. Retina 2007;27:707-12.
6. Mandal S, Venkatesh P, Sampangi R, et al. Intravitreal bevacizumab (Avastin) as primary treatment for myopic choroidal neovascularization. Eur J Ophthalmol 2007;17:620-6.

7. Chan WM, Lai TY, Liu DT, et al. Intravitreal bevacizumab (Avastin) for myopic choroidal neovascularization: six-month results of a prospective pilot study. Ophthalmology 2007;114:2190-6.

8. Ruiz-Moreno JM, Gomez-Ulla F, Montero JA, et al. Intravitreous bevacizumab to treat subfoveal choroidal neovascularization in highly myopic eyes: short-term results. Eye. Published Online First: 7 December 2007. doi:10.1038/sj.eye.6703052.

9. Arias L, Planas N, Prades S, et al. Intravitreal bevacizumab (Avastin) for choroidal neovascularisation secondary to pathological myopia: 6-month results. Br J Ophthalmol 2008;92:1035-9.

10. Verteporfin in Photodynamic Therapy Study Group. Photodynamic therapy of subfoveal choroidal neovascularization in pathologic myopia with verteporfin. 1-year results of a randomized clinical trial-VIP report no. 1. Ophthalmology 2001;108:841-52.

11. Blinder KJ, Blumenkranz MS, Bressler NM, et al. Verteporfin therapy of subfoveal choroidal neovascularization in pathologic myopia: 2-year results of a randomized clinical trial-VIP report no. 3 . Ophthalmology 2003;110:667-73.

12. Pece A, Isola V, Vadala M, et al. Photodynamic therapy with verteporfin for subfoveal choroidal neovascularization secondary to pathologic myopia: long-term study. Retina 2006;26:746-51.

13. Costa RA, Williams GA. Twofold illumination photodynamic therapy scheme for subfoveal choroida neovascularization in pathologic myopia: results from a randomized pilot study. Retina 2006;26:757-64.

14. Chan WM, Lai TY, Wong AL, et al. Combined photodynamic therapy and intravitreal triamcinolone injection for the treatment of choroidal neovascularisation secondary to pathological myopia: a pilot study. Br J Ophthalmol 2007;91:174-9.

15. Marticorena J, Gomez-Ulla F, Fernandez M, et al. Combined photodynamic therapy and intravitreal triamcinolone acetonide for the treatment of myopic subfoveal choroidal neovascularization. Am J Ophthalmol 2006;142:335-7.

16. Kojima A, Ohno-Matsui K, Teramukai S, et al. Estimation of visual outcome without treatment in patients with subfoveal choroidal neovascularization in pathologic myopia. Graefes Arch Clin Exp Ophthalmol 2006;244:1474-9.

17. Yoshida T, Ohno-Matsui K, Ohtake $Y$, et al. Longterm visual prognosis of choroidal neovascularization in high myopia: a comparison between age groups. Ophthalmology 2002;109:712-19.

18. Axer-Siegel R, Ehrlich R, Weinberger D, et al. Photodynamic therapy of subfoveal choroidal neovascularization in high myopia in a clinical setting: visual outcome in relation to age at treatment. Am J Ophthalmol 2004;138:602-7.

19. Wong D, Kyle G. Some ethical considerations for the "off-label" use of drugs such as Avastin. Br J Ophthalmol 2006;90:1218-19.

20. Rosenfeld PJ. Intravitreal Avastin for choroidal neovascularisation in pathological myopia: the controversy continues. $\mathrm{Br} \mathrm{J}$ Ophthalmol 2007; 91:128-30.

21. Health Technology Assessment Programme, National Institute for Health Research (NIHR), National Health Service, United Kingdom. A randomised controlled trial (RCT) of alternative treatments to Inhibit VEGF in patients with Age-related choroidal Neovascularisation (IVAN), ISRCTN reference no. 92166560. http://www. hta.ac.uk/project/1625.asp (accessed 25 May 2008). 